\title{
Fermentação ruminal de ovinos alimentados com alto concentrado e grãos de girassol ou gordura protegida
}

\author{
[Ruminal fermentation of sheep fed high-concentrated diet containing sunflower grains or protected fat] \\ A.C. Homem Junior ${ }^{1}$, J.M.B. Ezequiel ${ }^{2}$, V.R. Fávaro $^{1}$, P.S.N. Oliveira ${ }^{1}$, A.P. D'Aurea ${ }^{1}$, \\ V.C. Santos ${ }^{1}$, J.S. Gonçalves ${ }^{1}$ \\ ${ }^{1}$ Aluno de pós-graduação - FCAV-UNESP - Jaboticabal, SP \\ ${ }^{2}$ Faculdade de Ciências Agrárias e Veterinárias - UNESP - Jaboticabal, SP
}

\begin{abstract}
RESUMO
Seis ovinos machos, não castrados, da raça Santa Inês, com média de peso de $30 \mathrm{~kg}$, fistulados no rúmen, foram distribuídos em delineamento de quadrado-latino duplo (3x3). Três períodos e três dietas, uma controle, sem inclusão de fonte de lipídio, e duas com inclusão de grãos de girassol ou gordura protegida, foram testados quanto aos parâmetros ruminais. Foram verificadas diferenças $(\mathrm{P}<0,05)$ entre as dietas quanto à concentração ruminal de amônia $(18 \mathrm{mg} / \mathrm{dL})$, mas não houve efeito sobre o pH $(6,1)$, a produção total de ácidos graxos de cadeia curta $(98 \mathrm{mM})$, a proporção de acetato $(66,4 \%)$, de propionato $(20 \%)$ e de butirato (13\%) e sobre a razão acetato:propionato (3,2:1). As bactérias sólido-aderidas isoladas do conteúdo ruminal dos animais recebendo a dieta-controle apresentaram maior teor de nitrogênio $(10,7 \%)$ que as das dietas com gordura protegida $(9,8 \%)$ ou com grãos de girassol $(9,1 \%)$. A produção de nitrogênio pelas bactérias sólido-aderidas da dieta-controle $(170 \mathrm{mg} / \mathrm{g})$ não diferiu da dieta com grãos de girassol $(153 \mathrm{mg} / \mathrm{kg})$ ou com gordura protegida $(160 \mathrm{mg} / \mathrm{kg})$. A inclusão de grãos de girassol ou gordura protegida na dieta com alto concentrado para ovinos propiciou ambiente adequado para fermentação ruminal.
\end{abstract}

Palavras-chave: ovino, ácidos graxos de cadeia curta, amônia, bactérias ruminais, lipídios

\begin{abstract}
Six not castrated Santa Inês breed male sheep, weighing $30 \mathrm{~kg}$, fistulated in the rumen, were randomly alloted in a double Latin-Square design (3x3). Three periods and three diets, a control without addition of the lipid source, and two with addition of sunflower seeds or protected fat, were tested on the ruminal fermentation. Differences $(P<0.05)$ between diets for ruminal ammonia concentration $(18 m g / d L)$ were observed. However, effects were not detected on $\mathrm{pH}$ (6.1); the total production of short-chain fatty acids $(98 \mathrm{mM})$; proportions of acetate (66.4\%), propionate (20\%), and butyrate (13\%); and acetate:propionate ratio (3.2:1). The solid-adherent bacteria isolated from the rumen content of animals fed control diet had higher nitrogen content (10.7\%) than those fed protected fat diet $(9.8 \%)$ or sunflower seeds diet $(9.1 \%)$. The production of nitrogen by bacteria attached to solid-control diet $(170 \mathrm{mg} / \mathrm{kg})$ did not differ from sunflower seeds $(153 \mathrm{mg} / \mathrm{kg})$ or protected fat diets $(160 \mathrm{mg} / \mathrm{kg})$. The inclusion of sunflower seeds or protected fat in diets with high concentrate for sheep provided suitable environment for rumen fermentation.
\end{abstract}

Keywords: sheep, short-chain fatty acids, ammonia, ruminal bacteria, lipids

Recebido em 29 de julho de 2009

Aceito em 26 de novembro de 2009

E-mail: achomemj@hotmail.com

Projeto financiado pela FAPESP 


\section{INTRODUÇÃO}

Os parâmetros fermentativos do rúmen podem ser modificados pela adição de fontes de lipídio à dieta, porém a extensão dessa interferência depende tanto da fonte como da porcentagem de adição à ração. A maioria dos trabalhos confirma que o uso de lipídios exerce pouco ou nenhum efeito sobre as atividades microbianas $\mathrm{e}$ as demais características do ambiente ruminal, desde que não ultrapasse o valor de $7 \%$ da matéria seca total da dieta (Maia et al., 2006). A presença de lipídios insaturados em rações pode estimular as bactérias ruminais produtoras de propionato e, concomitantemente, reduzir a produção de acetato e butirato (Van Nevel e Demeyer, 1988).

$\mathrm{O}$ pH ruminal está diretamente relacionado com os produtos finais da fermentação e também com a taxa de crescimento dos microrganismos ruminais. Segundo Orskov (1986), o abaixamento do $\mathrm{pH}$ ruminal ocorre, principalmente, após a ingestão de alimentos, especialmente concentrados, devido à sua rápida taxa de fermentação.

Mehrez et al. (1977) afirmaram que o máximo de atividade fermentativa ruminal é obtido quando a amônia ruminal alcança valores entre 19 e 23mg/dL. Van Soest (1994) citou como nível ótimo $10 \mathrm{mg} / \mathrm{dL}$. Todavia, este valor não deve ser considerado como um número fixo, devido ao fato de a capacidade de síntese de proteína e captação de amônia pelas bactérias depender da taxa de fermentação dos carboidratos.

O objetivo deste trabalho foi avaliar o $\mathrm{pH}$, a concentração de amônia, a produção e composição de ácidos graxos de cadeia curta do líquido e das bactérias líquido-associadas e sólido-aderidas do conteúdo ruminal de ovinos que receberam dietas com alto concentrado contendo grãos de girassol e gordura protegida.

\section{MATERIAL E MÉTODOS}

Seis ovinos machos, não castrados, da raça Santa Inês, com média de peso corporal de $30 \mathrm{~kg}$, fistulados no rúmen com cânula permanente, foram distribuídos em um delineamento de quadrado-latino duplo, realizados ao mesmo tempo, composto por três dietas e três períodos, arranjados em parcela subdividida, com a dieta na parcela e o tempo na subparcela. Adotou-se o nível de significância de $5 \%$ para as análises estatísticas. O efeito da dieta foi estudado por uma análise de variância e compararam-se as médias pelo teste Tukey. $\mathrm{O}$ efeito do tempo foi analisado por regressão.

Os animais foram alojados em baias individuais, onde receberam alimentação à vontade, com pelo menos $15 \%$ de sobras, dividida em duas refeições diárias às 8 e 16 horas. A relação volumoso:concentrado da dieta foi de 18:82, tendo como volumoso o feno de Tifton-85, triturado em partículas de aproximadamente $5 \mathrm{~cm}$, que foi misturado ao concentrado antes do fornecimento. Os tratamentos consistiram de três dietas: a primeira foi usada como controle, sem adição de fonte de lipídio, a segunda continha grãos de girassol e a terceira, gordura protegida. As duas últimas continham as fontes de lipídios que as nomeiam.

$\mathrm{Na}$ Tab. 1, consta a composição em ingrediente e nutricional das dietas. As análises nutricionais foram realizadas segundo metodologias descritas por Silva e Queiroz (2002), exceto para o extrato etéreo, que foi de acordo com metodologia de extração ácida segundo a AOAC (Official..., 1995).

Manualmente, foram retiradas amostras de conteúdo ruminal nos tempos $0,2,5$ e 8 horas após a alimentação. Em camadas de pano fino (fraldas), foi separada a fase líquida da fase sólida do conteúdo ruminal para separação, quantificação e qualificação das bactérias líquido-associadas e bactérias sólido-aderidas de acordo com metodologia adaptada de Martin et al. (1994). Não foi possível isolar os protozoários do conteúdo ruminal, possivelmente pela elevada proporção de concentrado na dieta ou pela alta concentração de extrato etéreo devido à inclusão de fontes lipídicas. Portanto, foram isoladas somente as bactérias do conteúdo ruminal dos ovinos.

Após obtenção do líquido do rúmen, determinouse o pH por meio de peagômetro de mesa e quantificou-se a concentração de amônia. A amônia foi quantificada por destilação de $2 \mathrm{~mL}$ de líquido ruminal em Kjeldahl, utilizando-se $\mathrm{KOH} 2 \mathrm{M}$ e titulação com ácido clorídrico $0,005 \mathrm{M}$, segundo metodologia utilizada por Vieira (1980). 
Tabela 1. Composição em ingrediente e nutricional das dietas (\% MS) para ovinos

\begin{tabular}{lccc}
\hline \multirow{2}{*}{ Ingrediente } & \multicolumn{3}{c}{ Dieta } \\
\cline { 2 - 4 } & Controle & Grãos de girassol & Gordura protegida \\
\hline Feno Tifton-85 & 18,0 & 18,0 & 18,0 \\
Polpa cítrica & 35,5 & 29,5 & 28,5 \\
Levedura de cana & 14,0 & 14,0 & 14,0 \\
Casca de soja & 8,0 & 8,0 & 8,0 \\
Farelo de girassol & 24,0 & 15,0 & 24,0 \\
Grãos de girassol & - & 15,0 & - \\
& & & 7,0 \\
Gordura protegida ${ }^{\circledR}$ & - & - & 0,5 \\
Mistura mineral & ${ }^{1}$ & 0,5 & \\
Nutricional & & & 90,3 \\
Matéria seca & 90,1 & 90,2 & 18,7 \\
Proteína bruta & 19,4 & 18,1 & 7,1 \\
Extrato etéreo & 2,6 & 6,4 & 51,2 \\
Fibra em detergente neutro & 49,3 & 51,4 & 7,2 \\
Matéria mineral & 5,5 & 5,2 & \\
\hline
\end{tabular}

${ }^{\circledR}$ Lacto-Plus.

${ }^{1}$ Níveis de garantia por kg= P: 50g; Ca: 150g; Na: 195g; Co: 20mg; Cu: 190mg; I: 40mg; Mn: 14,5mg; Zn: 2g; Se: $7 \mathrm{mg} ; \mathrm{F}: 0,5 \mathrm{~g}$

Foram congeladas $100 \mathrm{~mL}$ de amostras do líquido para posterior quantificação dos ácidos graxos de cadeia curta acético, propiônico, butírico e total. As amostras foram descongeladas em geladeira antes de se realizar as análises. Os ácidos graxos de cadeia curta foram determinados por cromatografia líquido-gasosa.

\section{RESULTADOS E DISCUSSÃO}

Não foi detectado efeito da interação tempo $\mathrm{x}$ tratamento, assim como QL x tratamento para os parâmetros analisados $(\mathrm{P}>0,05)$.

A concentração de amônia ruminal foi influenciada $(\mathrm{P}<0,05)$ pela inclusão de lipídios às dietas, no entanto não houve efeito do tempo de coleta $(\mathrm{P}>0,05)$, o que pode ser explicado pela disponibilidade de alimento no cocho, fornecido à vontade. Animais que receberam fonte de lipídio na dieta apresentaram maiores teores de amônia ruminal que aqueles da dieta-controle. Houve superioridade de 19 e $29 \%$ das concentrações médias de amônia para as dietas com grãos de girassol e gordura protegida, respectivamente, em relação à dieta-controle. Esperava-se redução na concentração de amônia ruminal devido à presença de lipídio na dieta, mas verificou-se o oposto, talvez devido ao efeito tóxico dos lipídios, que exerceu influência no aproveitamento da amônia ruminal. O pico de amônia ruminal ocorreu às 2 e 8 horas após a alimentação, mas não houve efeito do tempo sobre a concentração (Fig. 1).

A concentração de amônia da dieta-controle $(15,0 \mathrm{mg} / \mathrm{dL})$ e das dietas com grãos de girassol $(18,6 \mathrm{mg} / \mathrm{dL})$ e com gordura protegida $(21,2 \mathrm{mg} / \mathrm{dL})$ está dentro da faixa de valores ótimos para máxima atividade fermentativa. Valores mais altos que os relatados neste trabalho foram obtidos por Silva et al. (2007), que, em dietas para cabras, utilizaram aproximadamente $17 \%$ de proteína bruta e obtiveram teor de amônia maior que $26,7 \mathrm{mg} / \mathrm{dL}$ e redução na concentração de amônia devido à inclusão de lipídio à dieta. Resultados semelhantes foram obtidos por Jenkins e Fotouhi (1990) e Ivan et al. (2003) para ovinos. 

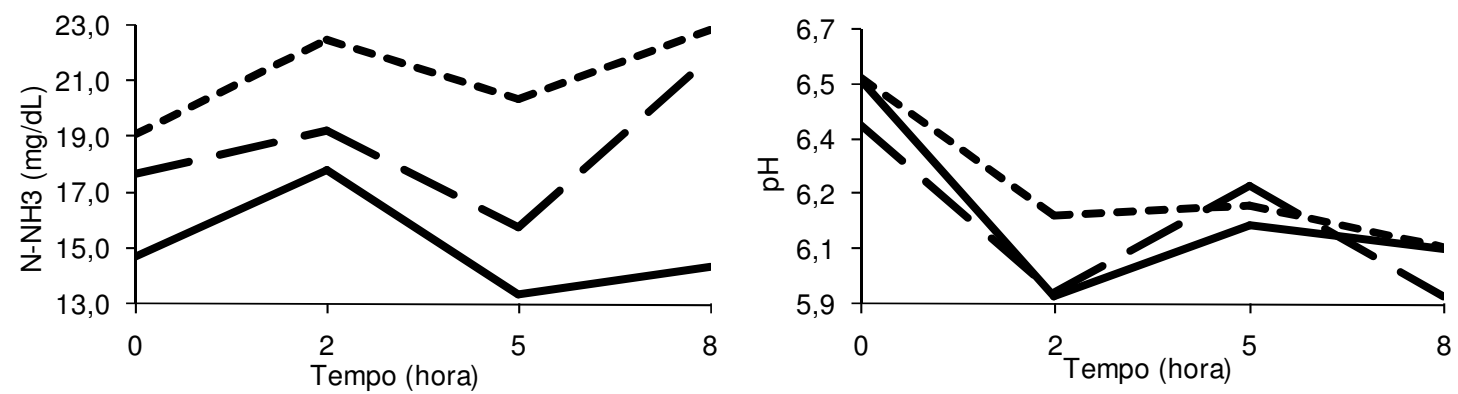

Figura 1. Nitrogênio amoniacal (N-NH3) e pH pós-prandial de ovinos que receberam dieta-controle (linha contínua), grãos de girassol (linha tracejada) e gordura protegida (linha pontilhada).

O pH ruminal, parâmetro indicativo da fermentação ruminal, não foi modificado pela dieta $(\mathrm{P}>0,05)$ e apresentou valor mínimo duas horas após a alimentação, com exceção da dieta com gordura protegida, nesta o valor mínimo de pH foi observado oito horas após a alimentação. $\mathrm{Na}$ média, o pH oscilou entre 6,5 e 6,0 nos tempos de 0 e 8 horas após alimentação e apresentou comportamento cúbico pela regressão com o tempo após alimentação $\left(-0,009 \mathrm{x}^{3}+\right.$ $\left.0,126 \mathrm{x}^{2}-0,452 \mathrm{x}+6,47 ; \mathrm{R}^{2}=1 ; \mathrm{P}<0,05\right) . \mathrm{Em}$ dietas com elevada proporção de concentrado, o $\mathrm{pH}$ abaixa rapidamente, podendo atingir valores muito ácidos que comprometem a saúde do rúmen, principalmente quando a fonte energética for o amido. Ao utilizar a polpa cítrica, a redução pode ser menos drástica.

Ivan et al. (2003) verificaram aumento no $\mathrm{pH}$ ruminal de 6,1 para 6,5 devido à inclusão de $14 \%$ de grãos de girassol na dieta de ovinos. Outros autores não detectaram efeitos da inclusão de gordura protegida ou óleo de soja sobre o $\mathrm{pH}$ do rúmen (Ngidi et al., 1990; Kucuk et al., 2004; Valinote et al., 2005). Segundo Hightshoe et al. (1991), em bovinos mantidos em pastagens e suplementados com fontes lipídicas protegidas, houve redução do $\mathrm{pH}$ de 6,46 para 6,39 pelo uso de gordura animal e elevação de 6,46 para 6,64 devido ao uso de óleo vegetal, o que permite inferir que a fonte de lipídio influencia os valores de $\mathrm{pH}$.

Não houve influência da inclusão de lipídio à dieta sobre a concentração total de ácidos graxos de cadeia curta e também sobre a concentração de ácidos acético, propiônico e butírico. A diferença, não significativa $(\mathrm{P}>0,05)$ da concentração total de ácidos graxos de cadeia curta, foi de apenas 5 e $9 \%$ entre as dietas com grãos de girassol e gordura protegida, respectivamente, em relação à dieta-controle. Foi obtido efeito quadrático do tempo sobre a concentração dos ácidos graxos de cadeia curta total (Tab. 2).

Ivan et al. (2003) não verificaram efeito da inclusão de grãos de girassol na dieta sobre o total de ácidos graxos de cadeia curta produzidos no rúmen, que variou de 71 a $100 \mathrm{mM}$. Jenkins e Fotouhi (1990) relataram que não houve diferença no total de ácidos no rúmen de ovinos que receberam dieta-controle $(64,7 \mathrm{mM})$, ou dieta com inclusão de lecitina $(54,1 \mathrm{mM})$ ou óleo de soja $(62,0 \mathrm{mM})$.

A polpa cítrica na dieta pode estar relacionada à produção de acetato no rúmen, diferente do milho que, em alta concentração, propicia produção de ácido lático que influencia a redução do $\mathrm{pH}$ e a digestão da fibra, e reduz a produção acética. $\mathrm{O}$ não efeito da inclusão de lipídio sobre a concentração de ácido acético indica que o ambiente é adequado para a fermentação da fibra.

Em dietas com elevada proporção de concentrado para bovinos, Ngidi et al. (1990) relataram que a inclusão de $4 \%$ de lipídios protegidos elevou o total de ácidos graxos de cadeia curta de 106 para $116 \mathrm{mM}$. No entanto, Machmüller et al. (2000) verificaram que o total de ácidos graxos de cadeia diminuiu de 150 para $115 \mathrm{mM}$ em uma dieta-controle em relação à outra com inclusão de grãos de girassol 
Tabela 2. Concentração ruminal (mM) nos tempos 0, 2, 5 e 8 horas após alimentação e média dos ácidos graxos de cadeia curta de ovinos que receberam dietas controle ou com inclusão de fontes de lipídios

\begin{tabular}{|c|c|c|c|c|c|}
\hline \multirow[b]{2}{*}{ Tempo } & \multicolumn{3}{|c|}{ Dieta } & \multirow{2}{*}{ Média } & \multirow{2}{*}{$\mathrm{CV}(\%)$} \\
\hline & Controle & Grãos de girassol & Gordura protegida & & \\
\hline \multicolumn{6}{|c|}{ Total } \\
\hline 0 & 74,5 & 77,8 & 88,8 & $80,4^{1}$ & \multirow{5}{*}{27,4} \\
\hline 2 & 96,4 & 109,8 & 111,9 & 106,0 & \\
\hline 5 & 107,7 & 101,4 & 104,7 & 104,6 & \\
\hline 8 & 93,6 & 102,3 & 103,7 & 99,9 & \\
\hline Média & 93,0 & 97,8 & 102,3 & & \\
\hline \multicolumn{6}{|c|}{ Acético } \\
\hline 0 & 49,5 & 51,3 & 61,1 & $54,0^{2}$ & \multirow{5}{*}{3,7} \\
\hline 2 & 64,2 & 70,3 & 73,2 & 69,2 & \\
\hline 5 & 71,0 & 66,7 & 69,2 & 69,0 & \\
\hline 8 & 62,3 & 65,5 & 70,1 & 66,0 & \\
\hline Média & 61,7 & 63,4 & 68,4 & & \\
\hline \multicolumn{6}{|c|}{ Propiônico } \\
\hline 0 & 14,9 & 16,1 & 16,5 & $15,8^{3}$ & \multirow{5}{*}{10,4} \\
\hline 2 & 20,3 & 23,8 & 24,7 & 22,9 & \\
\hline 5 & 23,8 & 21,7 & 24,0 & 23,2 & \\
\hline 8 & 20,2 & 23,9 & 21,4 & 21,8 & \\
\hline Média & 19,8 & 21,4 & 21,6 & & \\
\hline \multicolumn{5}{|c|}{ Butírico } & \multirow{6}{*}{8,2} \\
\hline 0 & 10,0 & 10,2 & 11,3 & $10,5^{4}$ & \\
\hline 2 & 11,9 & 15,6 & 14,0 & 13,8 & \\
\hline 5 & 12,9 & 13,1 & 11,5 & 12,5 & \\
\hline 8 & 11,1 & 13,0 & 12,2 & 12,1 & \\
\hline Média & 11,5 & 13,0 & 12,2 & & \\
\hline
\end{tabular}

Médias não diferem entre si pelo teste Tukey $(\mathrm{P}>0,05)$.

${ }^{1} \hat{Y}=-1,11 \mathrm{x}^{2}+10,8 \mathrm{x}+82,9\left(\mathrm{R}^{2}=0,84\right) ;{ }^{2} \hat{Y}=66,3 ;{ }^{3} \hat{Y}=-0,102 \mathrm{x}^{2}+1,06 \mathrm{x}+19,45\left(\mathrm{R}^{2}=0,95\right) ;{ }^{4} \hat{Y}=0,012 \mathrm{x}^{2}-0,264 \mathrm{x}+$ $13,29\left(\mathrm{R}^{2}=0,80\right)$.

$\mathrm{CV}=$ Coeficiente de variação.

No geral, os picos de concentração ruminal de ácidos graxos de cadeia curta ocorreram entre $2 \mathrm{e}$ 5 horas para a dieta-controle, e entre 0 e 2 horas após alimentação, para dietas com grãos de girassol e gordura protegida. Esse padrão de curva foi também constatado para o total de ácidos e para os ácidos acético, propiônico e butírico.

Verificou-se efeito linear do tempo sobre sua concentração do ácido butírico no líquido ruminal.

A relação acetato/propionato não diferiu $(P>0,05)$ entre as dietas com ou sem inclusão de grãos de girassol ou gordura protegida. A menor relação (3:1) foi encontrada nos tempos de 2 e 5 horas, e a maior relação, no tempo de 0 hora após a alimentação, o que resultou em efeito quadrático do tempo sobre a razão (Tab. 3).
Alta proporção de volumoso resulta em maior razão acetato/propionato, como 4,5 (Hightshoe et al., 1991). Em dieta com grande quantidade de concentrado, a razão pode ser de 1,7 a 1,3 (Ngidi et al., 1990; Kucuk et al., 2004). Neste trabalho, a inclusão de lipídio na dieta não alterou essa razão. Jenkins e Fotouhi (1990), ao incluirem lecitina $(3,17)$ ou óleo de milho $(3,25)$ em uma dieta-controle $(3,35)$, e Ngidi et al. (1990), ao adicionarem $6,0 \%$ de gordura protegida a uma dieta-controle, verificaram razões de 1,93 e 1,73, respectivamente, devido à inclusão.

Não foram detectadas diferenças $(\mathrm{P}>0,05)$ entre as dietas quanto à proporção dos ácidos graxos de cadeia curta (Fig. 2). Os valores médios foram de $66 \%$ de acético, $20 \%$ de propiônico e $13 \%$ de butírico. Valores semelhantes foram observados por Jenkins e Fotouhi (1990), que avaliaram a inclusão de lecitina ou do óleo de milho na dieta e relataram porcentagens de 63,1 para o acetato, 20,0 para o propionato e 13,2 para o butirato. 
Fermentação ruminal de ovinos...

Tabela 3. Razão acetato/propionato nos tempos 0, 2, 5 e 8 horas após a alimentação

\begin{tabular}{|c|c|c|c|c|c|}
\hline \multirow[b]{2}{*}{ Tempo $^{1}$} & \multicolumn{3}{|c|}{ Dieta } & \multirow[b]{2}{*}{ Média } & \multirow{2}{*}{$\mathrm{CV}(\%)$} \\
\hline & Controle & Grãos de girassol & Gordura protegida & & \\
\hline 0 & 3,5 & 3,4 & 3,8 & 3,6 & \multirow{5}{*}{11,8} \\
\hline 2 & 3,3 & 2,9 & 3,1 & 3,1 & \\
\hline 5 & 3,1 & 3,1 & 3,0 & 3,1 & \\
\hline 8 & 3,4 & 2,9 & 3,3 & 3,2 & \\
\hline Média & 3,3 & 3,1 & 3,3 & & \\
\hline
\end{tabular}

Médias não diferem entre si pelo teste Tukey $(\mathrm{P}>0,05)$.

${ }^{1} \hat{Y}=0,022 \mathrm{x}^{2}-0,215 \mathrm{x}+3,54\left(\mathrm{R}^{2}=0,92\right)$.

$\mathrm{CV}=$ coeficiente de variação.

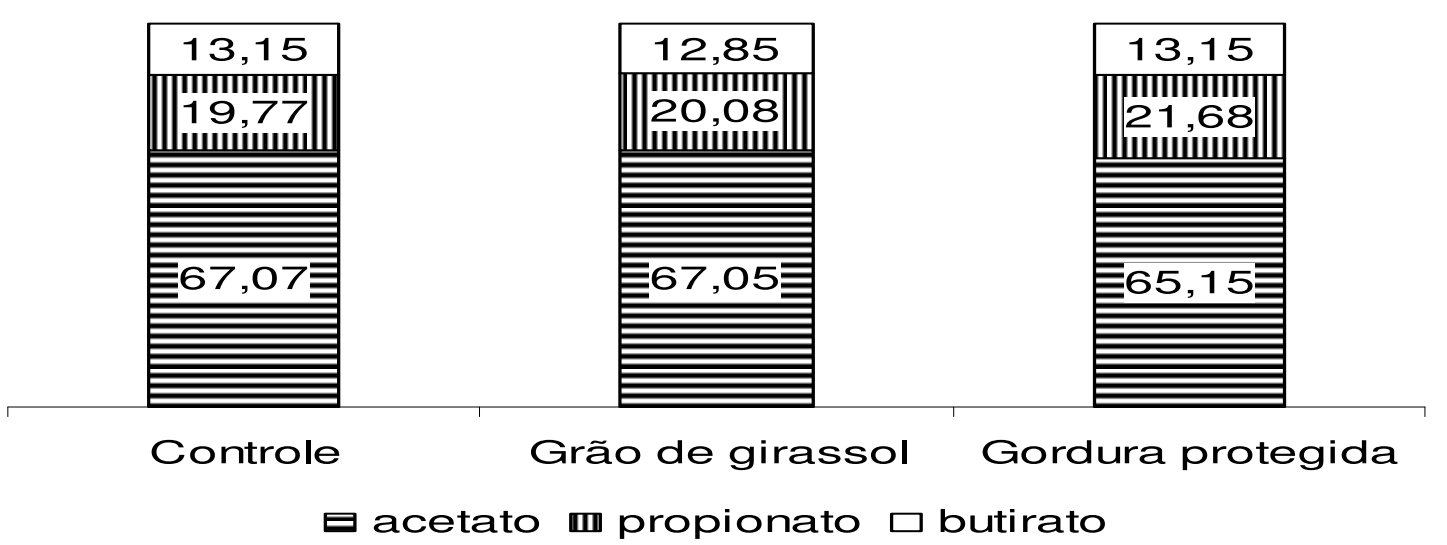

Figura 2. Proporção molar (\%) dos ácidos graxos de cadeia curta acetato, propionato e butirato do rúmen de ovinos confinados.

A produção de matéria seca, de matéria orgânica e de nitrogênio pelas bactérias líquido-associadas não foi modificada $(\mathrm{P}>0,05)$ pela introdução de grãos de girassol ou gordura protegida na dieta dos ovinos. As menores quantidades de matéria orgânica e de nitrogênio podem ser visualizadas no primeiro tempo de coleta, e as maiores produções no último tempo de coleta, dando ideia do crescimento que ocorre após a alimentação. No entanto, nenhum efeito foi detectado em função do tempo de coleta (Tab. 4).

Foi detectado efeito $(\mathrm{P}<0,05)$ da dieta sobre a composição em nitrogênio das bactérias líquidoassociadas. A dieta com grãos de girassol proporcionou menor teor de nitrogênio, refletindo o menor aproveitamento do nitrogênio revelado nos teores mais elevados de amônia ruminal. O lipídio atua diretamente sobre a eficiência de síntese de nitrogênio microbiano, pois não contribui como energia para os microrganismos do rúmen, ou indiretamente, devido à defaunação que gera sobre a população de protozoários, porém não há consenso sobre o envolvimento da defaunação e sobre a relação com o aumento da eficiência de síntese de nitrogênio microbiano (Dewhurst et al., 2000).

Os resultados dependem da metodologia de isolamento utilizada e das inúmeras dietas que podem ser formuladas e que modificam $o$ suprimento de substrato fermentável, e consequentemente, o crescimento microbiano e sua composição.

O teor de nitrogênio foi maior para as bactérias sólido-aderidas do rúmen de ovinos que receberam a dieta-controle, seguido pelos da dieta grãos de girassol e gordura protegida $(\mathrm{P}<0,05)$. No entanto, a produção de nitrogênio não diferiu $(\mathrm{P}>0.05)$ entre as dietas (Tab. 5). 
Tabela 4. Produção e composição de bactérias líquido-associadas do rúmen de ovinos que receberam dieta-controle e dietas com inclusão de fontes de lipídios nos tempos 0, 2, 5 e 8 horas após alimentação

\begin{tabular}{|c|c|c|c|c|c|}
\hline \multirow{2}{*}{ Tempo } & \multicolumn{3}{|c|}{ Dieta } & \multirow{2}{*}{ Média } & \multirow{2}{*}{ CV (\%) } \\
\hline & Controle & Grãos de girassol & Gordura protegida & & \\
\hline \multicolumn{5}{|c|}{ Matéria seca, mg/L } & \multirow{6}{*}{22,6} \\
\hline 0 & 1803,9 & 2110,9 & 1931,6 & $1948,8^{1}$ & \\
\hline 2 & 2048,5 & 2276,0 & 1942,2 & 2088,9 & \\
\hline 5 & 1949,8 & 2014,5 & 1822,1 & 1928,8 & \\
\hline 8 & 2157,7 & 2346,8 & 2196,0 & 2233,2 & \\
\hline \multirow[t]{2}{*}{ Média } & 1990,0 & 2187,1 & 1973,0 & & \\
\hline & & Matéria orgânica & & & \multirow{6}{*}{4,2} \\
\hline 0 & 79,2 & 82,2 & 82,3 & $81,2^{2}$ & \\
\hline 2 & 82,4 & 77,9 & 81,9 & 80,7 & \\
\hline 5 & 80,7 & 82,8 & 80,1 & 81,2 & \\
\hline 8 & 82,0 & 82,4 & 79,9 & 81,4 & \\
\hline \multirow[t]{2}{*}{ Média } & 81,1 & 81,3 & 81,0 & & \\
\hline & & Matéria orgânica & & & \multirow{6}{*}{25,0} \\
\hline 0 & 1436,5 & 1706,1 & 1582,2 & $1574,9^{3}$ & \\
\hline 2 & 1691,6 & 1762,4 & 1590,1 & 1681,4 & \\
\hline 5 & 1595,2 & 1666,8 & 1470,9 & 1577,6 & \\
\hline 8 & 1769,1 & 1928,9 & 1760,0 & 1819,3 & \\
\hline \multirow[t]{2}{*}{ Média } & 1623,1 & 1766,1 & 1600,8 & & \\
\hline & & Nitrogênio, \% & & & \multirow{6}{*}{7,8} \\
\hline 0 & 12,2 & 11,2 & 12,0 & $11,8^{4}$ & \\
\hline 2 & 12,4 & 10,9 & 11,2 & 11,5 & \\
\hline 5 & 11,5 & 10,1 & 10,7 & 10,8 & \\
\hline 8 & 11,6 & 9,7 & 11,4 & 10,9 & \\
\hline \multirow[t]{2}{*}{ Média } & $11,9 \mathrm{a}$ & $10,5 b$ & $11,3 \mathrm{a}$ & & \\
\hline & & Nitrogênio, m & & & \multirow{6}{*}{25,1} \\
\hline 0 & 174,6 & 191,6 & 190,2 & $185,4^{5}$ & \\
\hline 2 & 208,9 & 192,4 & 180,4 & 193,9 & \\
\hline 5 & 187,6 & 167,7 & 158,8 & 171,4 & \\
\hline 8 & 208,6 & 186,1 & 202,4 & 199,0 & \\
\hline Média & 194,9 & 184,4 & 182,9 & & \\
\hline
\end{tabular}

Médias seguidas por letras distintas na linha diferem entre si pelo teste Tukey $(\mathrm{P}>0,05)$.

${ }^{1} \hat{Y}=2050,0 ;{ }^{2} \hat{Y}=81,7 ;{ }^{3} \hat{Y}=1663,3 ;{ }^{4} \hat{Y}=0,024 \mathrm{x}^{2}-0,31 \mathrm{x}+11,9\left(\mathrm{R}^{2}=0,92\right) ;{ }^{5} \hat{Y}=187,5 . \mathrm{CV}=$ coeficiente de variação

A composição em matéria orgânica e de nitrogênio das frações bacterianas obtidas foram de 80 e $77 \%$ de $\mathrm{MO}$ e 11 e $9,9 \%$ de $\mathrm{N}$, respectivamente, para bactérias líquidoassociadas e sólido-aderidas. Estes resultados assemelham-se aos obtidos por Cecava et al. (1990), que constataram valores de MO de 81,5 a $84,4 \%$ e de $\mathrm{N}$ de 8,5 a $9,1 \%$ para bactérias da fase líquida, e de $\mathrm{MO}$ de 82,5 a $84,6 \%$ e de $\mathrm{N}$ de 7,5 a $8,4 \%$ para as da fase sólida, respectivamente. Martin et al. (1994) relataram teores de MO para bactérias da fase líquida na faixa de 60 a $65 \%$, e para as de fase sólida de 77 a 78\%. Mendes et al. (2006) encontraram menores valores de matéria orgânica $(60 \%)$.
Neste trabalho, não houve efeito da inclusão de lipídio sobre a produção de nitrogênio pelas bactérias líquido-associadas, assim como para a produção de nitrogênio pelas bactérias sólidoaderidas. Segundo Jenkins e Fotouhi (1990), a inclusão de lipídio na dieta de ovinos foi acompanhada pelo aumento da produção de nitrogênio microbiano, que se elevou de 4,5 para $6 \mathrm{~g} /$ dia.

A produção de matéria orgânica proveniente das bactérias do líquido não foi afetada pela dieta, da mesma forma que para as bactérias do sólido $(\mathrm{P}>0,05)$. 
Fermentação ruminal de ovinos...

Tabela 5. Produção e composição de bactérias sólido-aderidas do rúmen de ovinos que receberam dietacontrole e dietas com inclusão de fontes de lipídios nos tempos $0,2,5$ e 8 horas após alimentação

\begin{tabular}{|c|c|c|c|c|c|}
\hline \multirow{2}{*}{ Tempo } & \multicolumn{3}{|c|}{ Dieta } & \multirow{2}{*}{ Média } & \multirow{2}{*}{$\mathrm{CV}(\%)$} \\
\hline & Controle & Grãos de girassol & Gordura protegida & & \\
\hline \multicolumn{5}{|c|}{ Matéria seca, mg/kg } & \multirow{6}{*}{2,3} \\
\hline 0 & 2765,1 & 2558,8 & 2946,6 & $2756,8^{1}$ & \\
\hline 2 & 2473,5 & 2420,2 & 2440,3 & 2444,7 & \\
\hline 5 & 2508,6 & 2606,9 & 2339,2 & 2484,9 & \\
\hline 8 & 2397,6 & 2447,5 & 2532,9 & 2459,3 & \\
\hline \multirow[t]{2}{*}{ Média } & 2536,2 & 2508,4 & 2564,8 & & \\
\hline & & Matéria orgâni & & & \multirow{6}{*}{4,2} \\
\hline 0 & 77,2 & 79,5 & 76,9 & $77,9^{2}$ & \\
\hline 2 & 75,0 & 78,2 & 75,6 & 76,3 & \\
\hline 5 & 75,8 & 75,5 & 76,7 & 76,0 & \\
\hline 8 & 76,8 & 79,9 & 76,5 & 77,7 & \\
\hline \multirow[t]{2}{*}{ Média } & 76,2 & 78,3 & 76,4 & & \\
\hline & & Matéria orgâni & /kg & & \multirow{6}{*}{3,1} \\
\hline 0 & 1870,9 & 1794,7 & 1953,5 & $1873,0^{3}$ & \\
\hline 2 & 1600,8 & 1694,6 & 1627,3 & 1640,9 & \\
\hline 5 & 1621,5 & 1690,4 & 1553,0 & 1621,6 & \\
\hline 8 & 1598,4 & 1719,9 & 1677,9 & 1665,4 & \\
\hline \multirow[t]{2}{*}{ Média } & 1672,9 & 1724,9 & 1702,9 & & \\
\hline & & Nitrogênio, & & & \multirow{6}{*}{7,8} \\
\hline 0 & 10,8 & 9,4 & 10,0 & $10,1^{4}$ & \\
\hline 2 & 10,1 & 8,6 & 9,6 & 9,4 & \\
\hline 5 & 11,1 & 9,4 & 9,8 & 10,1 & \\
\hline 8 & 10,8 & 9,1 & 9,9 & 9,9 & \\
\hline \multirow[t]{2}{*}{ Média } & $10,7 \mathrm{a}$ & $9,1 \mathrm{c}$ & $9,8 b$ & & \\
\hline & & Nitrogênio, & & & \multirow{6}{*}{3,8} \\
\hline 0 & 197,1 & 166,8 & 197,3 & $187,1^{5}$ & \\
\hline 2 & 158,6 & 144,4 & 154,3 & 152,4 & \\
\hline 5 & 176,3 & 159,3 & 151,6 & 162,4 & \\
\hline 8 & 171,1 & 153,2 & 166,9 & 163,7 & \\
\hline Média & 170,4 & 153,2 & 160,1 & & \\
\hline
\end{tabular}

Médias seguidas por letras distintas na linha diferem entre si pelo teste Tukey $(\mathrm{P}>0,05)$.

${ }^{1} \hat{Y}=2483,1 ;{ }^{2} \hat{Y}=77,2 ;{ }^{3} \hat{Y}=1659,6 ;{ }^{4} \hat{Y}=9,8 ;{ }^{5} \hat{Y}=162,2$.

$\mathrm{CV}=$ coeficiente de variação.

Craig et al. (1987) detectaram diferença entre a composição das bactérias do líquido e do sólido, com maior concentração de nitrogênio para as do líquido $(7,5 \%)$ em relação às do sólido $(6,4 \%)$. Também detectaram variação no teor nitrogenado em função do tempo após a alimentação, com valores mais altos para a primeira coleta, e redução de 9,2 para $7,7 \%$ no caso das bactérias do líquido e de 9,2 para $6,7 \%$ nas bactérias do sólido, nas primeiras horas. $\mathrm{O}$ retorno à concentração inicial ocorreu às seis horas após a alimentação. Olubobokum e Craig (1990) não verificaram alterações na concentração de nitrogênio em função do tempo de coleta do conteúdo, 2 e 23 horas após alimentação. Observaram, também, maior concentração de nitrogênio nas bactérias do líquido, 8,8\%. Esses autores verificaram que as produções de matéria orgânica e nitrogênio não diferiram em função do tempo de coleta. Olubobokum et al. (1988) relataram que os microrganismos aderidos ao sólido apresentamse em grande proporção na população microbiana do rúmen. Segundo esses autores, as bactérias sólido-aderidas apresentaram $88 \%$ de MO e as líquido-associadas, $80,2 \%$ de MO. O teor de nitrogênio foi de $8,8 \%$ para as do sólido e $9,7 \%$ para as do líquido.

Segundo Cecava et al. (1990), as mudanças na disponibilidade de matéria orgânica fermentável podem afetar a composição das bactérias 
ruminais por modificar a taxa de crescimento, as espécies presentes ou a associação das bactérias com as frações específicas (líquido e sólido) do rúmen. A redução da proporção de polpa cítrica nas dietas com inclusão de lipídios pode ter diminuído a energia disponível para o aproveitamento do nitrogênio amoniacal, refletindo na composição e produção de nitrogênio microbiano, resultando em menores teores e quantidades de nitrogênio de bactérias do líquido assim como nas do sólido.

Ezequiel et al. (2002) relataram teores de nitrogênio de 6,7 e 5,9\% para as frações líquidoassociadas e sólido-aderidas, respectivamente, valores inferiores ao deste trabalho, diferença que pode estar relacionada ao teor de proteína das dietas que neste trabalho foi mais elevado.

\section{CONCLUSÕES}

A inclusão de grãos de girassol ou gordura protegida na dieta de alto concentrado para ovinos propicia ambiente adequado para fermentação ruminal.

\section{REFERÊNCIAS BIBLIOGRÁFICAS}

CECAVA, M.J.; MERCHEN, N.R.; GAY, L.C. et al. Composition of ruminal bacteria harvested from steers as influenced by dietary energy level, feeding frequency, and isolation techniques. $J$. Dairy Sci., v.73, p.2480-2888, 1990.

CRAIG, W.M.; BROWN, D.R.; BRODERICK, G.A. et al. Post-prandial compositional changes of fluid-and particle-associated ruminal microorganisms. J. Anim. Sci., v.65, p.10421048, 1987.

DEWHURST, R.J.; DAVIES, D.R.; MERRY, R.J. Microbial protein supply from the rumen. Anim. Feed Sci. Technol., v.85, p.1-21, 2000.

EZEQUIEL, J.M.B.; MELÍCIO, S.P.L.; SANCANARI, J.B.D. et al. Quantificação das bactérias sólido-aderidas, bactérias e protozoários líquido-associados do rúmen de bovinos jovens alimentados com amiréia. Rev. Bras. Zootec., v.31, p.707-715, 2002.

HIGHTSHOE, R.B.; COCHRAN, R.C.; CORAH, L.R. et al. Effects of calcium soaps of fatty acids on postpartum reproductive function in beef cows. J. Anim. Sci., v.69, p.4097-4103, 1991.
IVAN, M.; ENTZ, T.; MIR, P.S. et al. Effects of sunflower seed supplementation and different dietary protein concentrations on the ciliate protozoa population dynamics in the rumen of sheep. Can. J. Anim. Sci., v.83, p.809-817, 2003.

JENKINS, T.C.; FOTOUHI, N. Effects of lecithin and corn oil on site of digestion, ruminal fermentation and microbial protein synthesis in sheep. J. Anim. Sci., v.64, p.460-466, 1990.

KUCUK, O.; HESS, B.W.; RULE, D.C. Soybean oil supplementation of a high-concentrate diet does not affect site and extent of organic matter, starch, neutral detergent fiber, or nitrogen digestion, but influences both ruminal metabolism and intestinal flow of fatty acids in limit-fed lambs. J. Anim. Sci., v.82, p.2985-2994, 2004.

MACHMÜLLER, A.; OSSOWSKI, D.A.; KREUZER, M. Comparative evaluation of the effects of coconut oil, oilseeds and crystalline fat on methane release, digestion and energy balance in lambs. Anim. Feed Sci. Technol., v.85, p.4160,2000 .

MAIA, F.J.; BRANCO, A.F.; MOURO, G.F. et al. Inclusão de fontes de óleo na dieta de cabras em lactação: produção, composição e perfil dos ácidos graxos do leite. Rev. Bras. Zootec., v.35, p.1504-1513, 2006.

MARTIN, C.; WILLIAMS, A.G.; MICHALETDOREAU, B. Isolation and Characteristics of the Protozoal and bacterial fractions from bovine ruminal contents. J. Anim. Sci., v.72, p.29622968, 1994.

MEHREZ, A.Z.; ORSKOV, E.R.; McDONALD, I. Rate of rumen fermentation in relation to ammonia concentration. Br. J. Nutr., v.38, p.437443, 1977.

MENDES, A.R.; EZEQUIEL, J.M.B.; GALATI, R.L. et al. Cinética digestiva e eficiência de síntese de proteína microbiana em novilhos alimentados com farelo de girassol e diferentes fontes energéticas. Rev. Bras. Zootec., v.35, p.264-274, 2006.

NGIDI, M.E.; LOERCH, S.C.; FLUHARTY, F.L. et al. Effects of calcium soaps of long-chain fatty acids on feedlot performance, carcass characteristics and ruminal metabolism of steers. J. Anim. Sci., v.68, p.2555-2565, 1990. 
OFFICIAL methodos of analysis of AOAC International. 16.ed. Arlington, VA: AOAC, 1995.

OLUBOBOKUM, J.A.; CRAIG, W.M. Quantity and characteristics of microorganisms associated with fluid or particles. J. Anim. Sci., v.68, p.3360-3370, 1990.

OLUBOBOKUM, J.A.; CRAIG, W.M.; NIPPER, W.A. Characteristics of protozoal and bacterial fractions from microorganisms associated with ruminal fluid or particles. $J$. Anim. Sci., v.66, p.2701-2710, 1988.

ORSKOV, E.R. Starch digestion and utilization by ruminants. J. Anim. Sci., v.63, p.1624-1633, 1986.

SILVA, D.J.; QUEIROZ, A.C. Análise de alimentos: métodos químicos e biológicos. 3.ed. Viçosa: UFV, 2002. 235p.

SILVA, M.M.C.; RODRIGUES, M.T.; RODRIGUES, C.A.F. et al. Efeito da suplementação de lipídios sobre a digestibilidade e os parâmetros de fermentação ruminal em cabras leiteiras. Rev. Bras. Zootec., v.36, p.246256, 2007.
VALINOTE, A.C.; NOGUEIRA FILHO, J.C.M.; LEME, P.R. et al. Fontes de lipídeos e monensina na alimentação de novilhos Nelore e sua relação com a população de protozoários ciliados do rúmen. Rev. Bras. Zootec., v.34, p.1418-1423, 2005.

Van NEVEL, C.; DEMEYER, D.I. Manipulation of rumen fermentation. In: HOBSON, H.D. (Ed.). The rumen microbial ecosystem. New York: Elsevier Science, 1988. p.387-443.

Van SOEST, P.J. Nutritional ecology of the ruminant. 2.ed. Ithaca, NY: Comstock, 1994. 476p.

VIEIRA, P.F. Efeito do formaldeído na proteção de proteína e lipídeos em rações para ruminantes. 1980. 98f. Tese (Doutorado) Universidade Federal de Viçosa, Viçosa, MG. 